\title{
A study of serum zinc levels in children admitted with pneumonia in a tertiary care hospital in India
}

\author{
Ashrin A Naushad', Lalitha Kailas ${ }^{2}$, Sreekanth K Sivaraman ${ }^{2}$ \\ From ${ }^{1}$ Postgraduate, ${ }^{2}$ Head, Department of Paediatrics, Sree Gokulam Medical College and Research Foundation, Venjarammoodu, Kerala, India
}

\begin{abstract}
Background: Worldwide, pneumonia is a leading cause of morbidity and mortality in children under 5 years of age; especially, in developing countries. Objectives: The objective of the study is to investigate whether zinc deficiency and other nutritional factors are related to pneumonia in children between 6 months and 5 years old. Methodology: In this casecontrol study, a valid written consent was obtained from mothers of enrolled children. The cases included 75 children fulfilling the World Health Organization criteria for pneumonia, between the age group of 6 months and 5 years. They were interrogated for potential nutritional risk factors as per a predesigned proforma followed by a measurement of serum zinc levels. In the control group, 75 children of the same age group who were siblings of admitted children were included along with other children of the same age group admitted for non-respiratory complaints. A detailed case history was obtained and physical examination was done according to a predesigned proforma to elicit various potential risk factors. A semi-auto analyzer was used to measure the serum zinc levels through colorimetric methods using 5-bromo-PAS. Results: Significant nutritional risk factors identified were low serum zinc level, malnutrition, and anemia. Conclusion: The present study has identified various nutritional risk factors for pneumonia which can be tackled through effective education of the community and appropriate initiatives.
\end{abstract}

Key words: Pneumonia, Zinc level, Nutritional risk factors, Anaemia

$\mathrm{P}$ neumonia continues to be the biggest killer all over the world for children under 5 years of age. Although the implementation of safe, effective, and affordable interventions has reduced the mortality rate from 4 million in 1981 to just over one million in 2013, pneumonia still accounts for nearly one-fifth of childhood deaths worldwide [1]. The incidence of pneumonia is more than 10-fold higher and the number of childhood-related deaths due to pneumonia is approximately 2000 -fold higher in developing countries than in developed countries [2]. Approximately $95 \%$ of the pneumoniarelated deaths occur in developing countries and the younger age groups have the highest risk of death [3]. These cases are severe enough to require hospitalization, creating a huge burden on hospital services [4].

There are certain social, economic, and environmental factors that are responsible for pneumonia. Socioeconomic status, severe malnutrition, and lack of breast feeding, particularly in the early months of life contribute to the development of pneumonia [5]. Elimination of most of the environmental risk factors for

\section{Access this article online}

Received - 15 October 2021

Initial Review - 21 December 2021

Accepted - 27 December 2021

DOI: $10.32677 /$ ijch.v8i12.3235 pneumonia is very difficult, but some nutritional factors need a simple intervention [6]. Malnutrition is estimated to contribute up to half of pneumonia-related deaths. While much emphasis is placed on Protein Energy Malnutrition and Vitamin A, it has been proposed that zinc can have a real potential in the prevention of pneumonia morbidity and mortality [7].

Zinc deficiency is common among children in developing countries because of inadequate food intake, particularly from animal sources, and limited zinc bioavailability from the local diets. Zinc deficiency impairs the immune system and increases the rate of serious infections such as pneumonia [6]. Observational studies and randomized controlled trials have revealed a range of detrimental functional outcomes associated with zinc status during childhood, including linear growth, motor development, and susceptibility to infectious diseases [8].

Zinc is reported to prevent pneumonia and is also known to prevent and treat diarrhea. In addition, it might play a major role in the acute phase response to infection, help to boost the body's immune response through a defense cascade, beginning with mobilization and sequestration of zinc to metallothioneinrich tissue, rapid up-regulation of immune defense specific protein synthesis, activation of immune defense activity

Correspondence to: Ashrin A Naushad, G-383, Panampilly Nagar, Kochi - 682 036, Kerala, India. E-mail: ashrin.naushad@gmail.com

(C) 2021 Creative Commons Attribution-NonCommercial 4.0 International License (CC BY-NC-ND 4.0). 
such as macrophages, lymphocytes, natural killer cells, and antibody-dependent cytotoxicity. Children with good zinc levels may have a more robust immune response than with poor zinc status [9]. Recommended zinc nutritional intake is $10-20 \mathrm{mg} /$ day for children. Normal serum zinc levels are $60-120 \mathrm{mg} / \mathrm{dl}[10]$.

\section{METHODOLOGY}

In this case-control study, after obtaining a valid written consent from mothers, 75 cases fulfilling the World Health Organization (WHO) criteria for pneumonia, in the age group 6 months- 5 year were interrogated for potential nutritional risk factors as per a predesigned proforma and serum zinc level was measured. In the control group, 75 children of the same age group who were normal siblings of admitted children were included along with other children of the same age group admitted for non-respiratory complaints. The study was carried out between December 2016 and December 2018.

A detailed case history and physical examination were done according to a predesigned proforma to elicit various potential risk factors. History of relevant symptoms such as fever, cough, rapid breathing, chest retractions, refusal to feed, lethargy, wheezing was noted. Anthropometry was done and malnutrition was graded according to IAP classification. Plasma zinc level was estimated by collecting $3 \mathrm{ml}$ of venous blood via venipuncture using zinc-free plastic tubes. The blood samples were transported to laboratory. Serum zinc concentration was measured using the colorimetric method with 5-bromo-PAPS using a semi-auto analyzer. During the entire study period, there was no deviation from the standard of care for the purpose of research.

\section{Statistical Analysis}

The data were entered into Microsoft Excel sheet and results were analyzed using Statistical Package for the Social Sciences software. The predictability of zinc level was analyzed independently and in combination, using Pearson Chi-square test/Fischer exact test with the outcome variable.

Odd's ratio was computed. $\mathrm{p} \leq 0.05$ was considered to be statistically significant. The sample size was calculated using the following formula: Sample size

$$
\text { (n): } \frac{1}{(\mathrm{P} 1-\mathrm{P} 2)^{2}}\left[\begin{array}{l}
\frac{\mathrm{Z} \alpha}{2} \sqrt{2 \mathrm{P} 2(1-\mathrm{P} 2)}+\mathrm{Z} \beta \sqrt{\mathrm{P} 1(1-\mathrm{P} 1)} \\
+\mathrm{P} 2(1-\mathrm{P} 2)
\end{array}\right]^{2}
$$

The values were taken from a previous study: $\mathrm{P} 1$ is anticipated probability of exposure among the cases $-0.983, \mathrm{P} 2$ is anticipated probability of exposure among the controls -0.643 , Alpha$1 \%$, Beta $-5 \%$. After substituting the values, $\mathrm{n}=57$ (a minimum requirement for each group). A sample size of cases and control was taken as 75 , because of assumption that low sample size will affect the outcome of the study.

\section{RESULTS}

The present study identified multiple nutritional risk factors for pneumonia. Out of the 75 cases, 54 patients $(72 \%)$ had serum zinc levels below the normal range of $60-120 \mu \mathrm{g} / \mathrm{dl}, 20$ patients (26.7\%) had normal zinc values and one patient (1.3\%) had zinc value above the normal level Thus, low serum zinc level was significantly associated with pneumonia with a $p=0.001$. Fig. 1 shows a distribution of serum zinc levels of cases and controls. The present study also demonstrated a statistically significant correlation between nutritional risk factors such as malnutrition, anemia, and serum zinc levels. Out of the 75 cases, five patients $(6.7 \%)$ had grade III malnutrition, 11 patients $(14.7 \%)$ had grade II malnutrition, 33 patients (44\%) had grade I malnutrition and 26 patients $(34.7 \%)$ had normal nutritional status. Malnutrition was significantly associated with pneumonia cases $(\mathrm{p}=0.005)$. Fig. 2 shows a distribution of malnutrition among cases and controls.

In our study, out of the 75 cases, 44 patients $(58.7 \%)$ had anemia. Thus, anemia was found to be significantly associated with pneumonia $(\mathrm{p}=0.034)$. Fig. 3 shows a distribution of anemia among cases and controls. There was also a statistically significant association between low serum zinc levels with malnutrition $(\mathrm{p}=0.041)$. Fig. 4 shows a correlation between

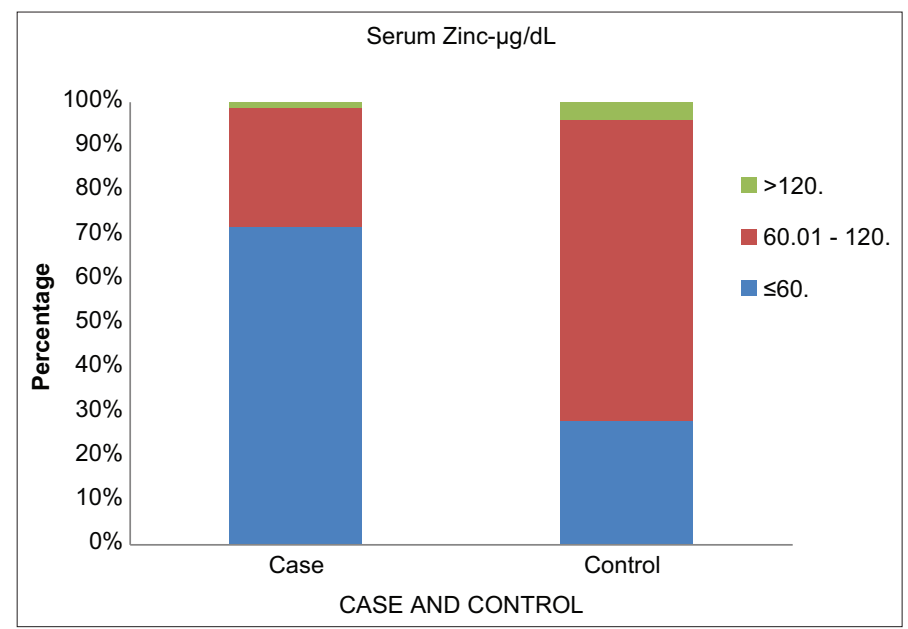

Figure 1: Distribution of serum zinc levels of cases and controls

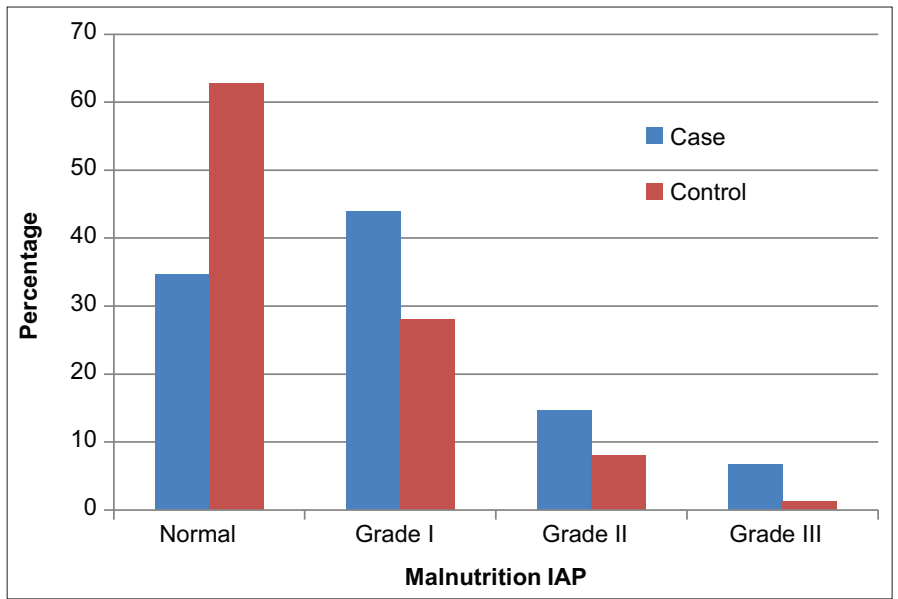

Figure 2: Distribution of malnutrition among cases and controls 


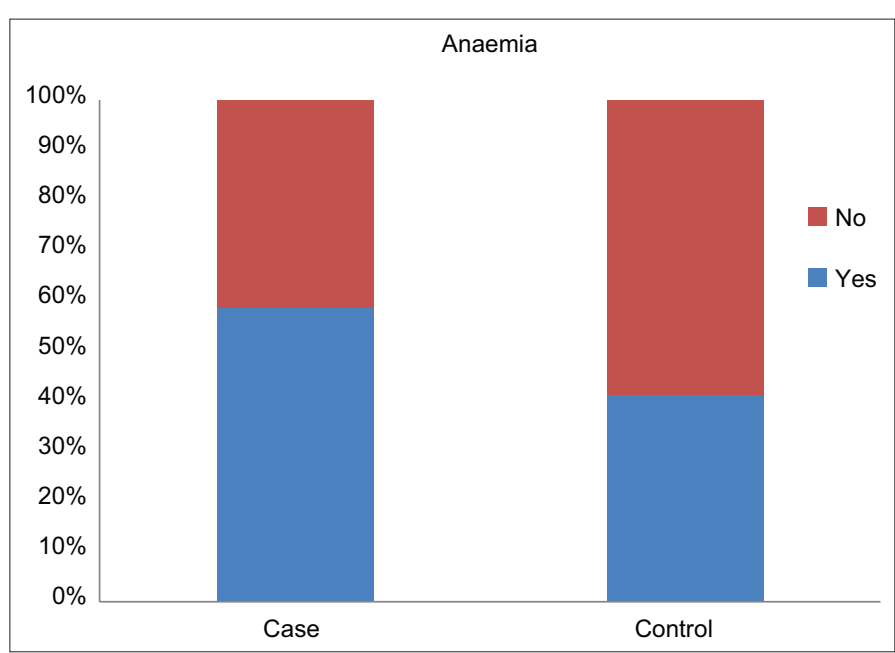

Figure 3: Distribution of anemia among cases and controls

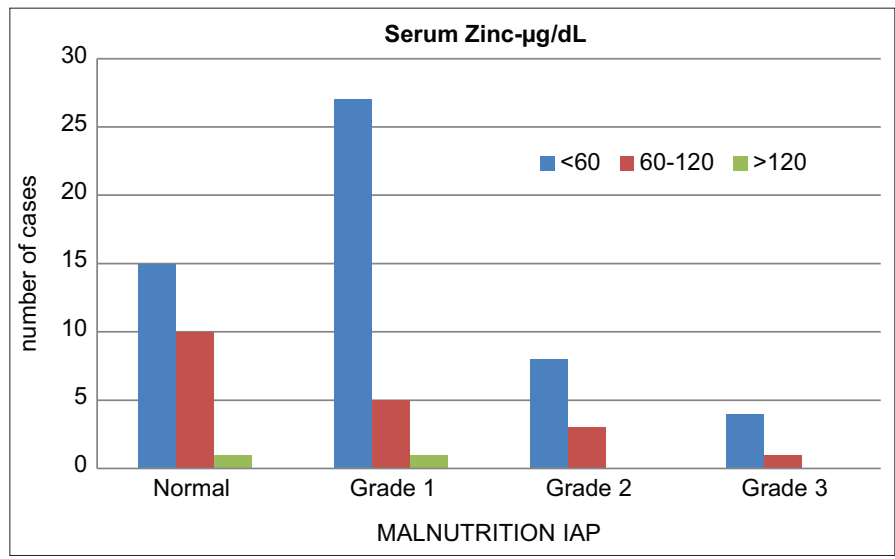

Figure 4: Correlation between malnutrition and serum zinc levels

malnutrition and serum zinc levels of cases. Lower serum zinc level was also significantly associated with anemia $(\mathrm{p}=0.007)$. Other factors such as age, sex, breast feeding, term/preterm, birth weight, a history of recurrent respiratory infection, immunization status, socio-economic status, environmental factors, and Vitamin A deficiency were not significantly associated with pneumonia.

\section{DISCUSSION}

Childhood pneumonia clearly represents one of the most common infective illnesses in developing countries and is of great importance as a cause of preventable mortality in children. To solve this global problem, the WHO shaped strategy for early diagnosis and effective case management that had remarkable impact on mortality due to childhood pneumonia in developing countries. Even after these measures, the burden caused by childhood pneumonia in terms of both mortality and morbidity is very high. It is, therefore, necessary to identify other etiological factors which contribute to the severity of pneumonia.

Influence of demographic, socioeconomic, and nutritional factors has been a matter of debate for quite a few years. Among the nutritional factors, Vitamin A deficiency, anemia, rickets, and zinc level is considered to be important. It is well known that zinc has a crucial role to play in immunity. However, an exact influence of zinc has not been outlined yet. Therefore, the present study was conducted keeping this view in mind. The objective of the study was to investigate whether zinc deficiency and other nutritional factors are related to pneumonia in children between 6 months and 5 years old. The present study has taken into consideration various nutritional factors such as malnutrition, anemia, serum zinc level, clinical findings of Vitamin A deficiency. We have also taken into consideration socio-demographic factors such as immunization status and socio-economic status into the study. The age and sex distributions were comparable between cases and controls.

Among the nutritional variables, malnutrition, anemia, and low serum zinc level were found to be significantly associated with pneumonia with a $\mathrm{p}=0.005,0.034$, and $<0.001$ respectively. The presence of malnutrition was significantly associated with pneumonia in the present study with $\mathrm{p}=0.005$, similar to other studies. A study in the Philippines included age-stratified risks in children less than 23 months of age and reported the highest risk of death from pneumonia due to malnutrition among those aged between 12 and 22 months.

A study in New Delhi revealed severe malnutrition as a predictor of mortality in acute lower respiratory infection (ALRI) in 2 weeks -5 years old children. Overall, malnutrition is associated with a 2-3 folds increase in mortality from ALRI. It is well known that malnourished children have defective cell-mediated immunity, secondary to thymolymphatic depletion leading to severe gram-negative infections and sepsis. Qualitatively, they may also have abnormal immunoglobulins and impairment of key enzymes involved in the bactericidal action of leucocytes.

Previous studies by Broor et al. [11] have reported that partially immunized children were more prone to develop pneumonia as compared to fully immunized children. But in our study, we did not find any significant association between partially immunized state and pneumonia. The most probable reason for that would be the lesser number of partially immunized children $(12 \%)$ in our study and we have taken the national immunization schedule as the standard.

Anemia was a significant factor for pneumonia in the present study. Not many studies have stressed on the role of anemia in pneumonia. There is an extensive debate regarding the role of anemia in infection. The proposed pathophysiological factors for increased risk of infections are-a decreased capacity of neutrophils to kill bacteria due to reduced myeloperoxidase activity and a defective DNA synthesis due to decreased ribonucleotide reductase activity. Both, the proportion and the absolute number of circulating $\mathrm{T}$ cells are reduced in anemia.

In this present study, low serum zinc level was found to have a significant association with pneumonia $(\mathrm{p}<0.001)$. It implies that, in the present study, children with pneumonia had significantly low serum zinc values which can be a predisposing factor for the infection. Even though there is a significant association between low serum zinc values and pneumonia, according to the present study, it does not imply that all the children having pneumonia will have low serum zinc values. It can be taken as 
one among the many causes predisposing for pneumonia. In this study, 20 cases $(26.7 \%)$ with pneumonia had normal zinc values. Moreover, children with pneumonia and low serum zinc level had other nutritional risk factors such as malnutrition and anemia. On analysis, malnutrition and low serum zinc level showed a suggestive significance with a $\mathrm{p}=0.001$. This implies low serum zinc level can be considered as a modifiable nutritional risk factor predisposing to pneumonia.

\section{CONCLUSION}

This study implies that in a developing country like India where incidence of pneumonia is alarmingly high, associated factors such as malnutrition, anemia, and low serum zinc level contribute to the mortality and morbidity of the condition. Since these factors are deficiency states, addressing them can help to reduce the incidence of pneumonia and reduce the financial burden on the country.

\section{REFERENCES}

1. World Health Organization. Revised WHO Classification and Treatment of Pneumonia in Children at Health Facilities. Geneva: World Health Organization; 2014.

2. Sandora TJ, Kelly MS. Community acquired pneumonia. In: Behrman RE, Kleigman RM, Stanton BF, editors. Nelson's Textbook of Pediatrics. $20^{\text {th }}$ ed.
Philadelphia, PA: Saunders Elsevier; 2016. p. 2088-94.

3. Kumar S, Awasthi S, Jain A, Srivastava RC. Blood zinc levels in children hospitalized with severe pneumonia. Indian Pediatr 2004;41:486-91.

4. Greenwood BM, Weber MW, Mulholland K. Childhood pneumonia preventing the world's biggest killer of children. Bull World Health Organ 2007;85:502-3.

5. Ganguly N. Lower respiratory tract infections in children. Pediatr Infect Dis 2006;98-105

6. Valavi E, Hakimzadeh M, Shamsizadeh A, Aminzadeh M, Alghasi A. The efficacy of zinc supplementation on outcome of children with severe pneumonia. Indian J Pediatr 2011;78:1079-84.

7. Ngom PT, Howie S, Ota MO, Prentice AM. The potential role and possible immunological mechanisms of zinc adjunctive therapy for severe pneumonia in children. Open Immunol J 2011;4:1-10.

8. Walker CL, Black RE. Functional indicators for assessing zinc deficiency. Food Nutr Bull 2007;28:454-79.

9. Hambidge KM. Zinc and pneumonia. Am J Clin Nutr 2006;83:991-2.

10. Ayieko P, English M. Should Zinc be used in the prevention and management of acute respiratory infections? Int Child Health Rev Collab 2006;79-84.

11. Broor S, Pandey RM, Ghosh M, Maitreyi RS, Lodha R, Singhal TS, et al. Risk factors for acute lower respiratory tract infections. Indian Pediatr 2001;38:1361-7.

Funding: None; Conflicts of Interest: None Stated.

How to cite this article: Naushad AA, Kailas L, Sivaraman SK. A study of serum zinc levels in children admitted with pneumonia in a tertiary care hospital in India. Indian J Child Health. 2021; 8(12):426-429. 